\title{
Hsp70 silencing with siRNA in nanocarriers enhances cancer cell death induced by the inhibitor of Hsp90
}

\author{
Mirela Matokanovic ${ }^{\text {a,c }}$, Karmela Barisic ${ }^{\text {a }}$ Jelena Filipovic-Grcic ${ }^{\mathrm{b}}$, Dusica Maysinger ${ }^{\mathrm{c}, *}$ \\ ${ }^{a}$ Department of Medical Biochemistry and Hematology, Faculty of Pharmacy and Biochemistry, University of Zagreb, Domagojeva 2, HR-10000 Zagreb, Croatia \\ ${ }^{\mathrm{b}}$ Department of Pharmaceutics, Faculty of Pharmacy and Biochemistry, University of Zagreb, Domagojeva 2, HR-10000 Zagreb, Croatia \\ ${ }^{\mathrm{c}}$ Department of Pharmacology and Therapeutics, McGill University, Montreal, QC, Canada H3G 1 Y6
}

\section{A R T I C L E I N F O}

\section{Article history:}

Received 28 December 2012

Received in revised form 18 March 2013

Accepted 1 April 2013

Available online 10 April 2013

\section{Keywords:}

Cancer

Hsp70

Chitosan

siRNA nanocarriers

Celastrol

Tumor spheroids

\begin{abstract}
A B S T R A C T
Inducers of heat shock protein 70 (Hsp70) commonly promote cancer cell viability whereas inhibitors of Hsp90 reduce it. The anticancer agent celastrol, interferes with signal transduction pathways involving these heat shock proteins. The objective of this in vitro study was to silence inducible Hsp70 and to promote celastrol-induced tumor cell death. Hsp70 siRNA loaded chitosan-TPP carriers were prepared by ionic gelation and characterized by photon correlation spectroscopy and asymmetric flow field-flow fractionation combined with dynamic light scattering. Viability of human leukemia and glioblastoma cells and Hsp70 silencing was determined following treatment with chitosan-TPP-Hsp70 siRNA particles. The results showed that silencing of Hsp70 by chitosan-TPP-Hsp70 siRNA treatment significantly reduced cell viability, and enhanced antiproliferative effects of celastrol in leukemia and glioblastoma cells. In glioblastoma spheroids, higher concentrations of celastrol and Hsp70 siRNA in chitosan-TPP nanocarriers were necessary to induce cell death.
\end{abstract}

(c) 2013 Elsevier B.V. All rights reserved.

\section{Introduction}

Mechanisms of cancer cell resistance towards chemotherapeutics are poorly understood, and increasing the efficiency of anticancer treatments by interfering with tumor defense mechanisms is a major objective of cancer biology research (Hanahan and Weinberg, 2000, 2011). Functional studies indicate that tumor resistance towards apoptosis and possibly other types of cell death can be reduced by diminishing the activity of the heat shock protein (HSP) family members (Beere et al., 2000; Clemons et al., 2005; Goloudina et al., 2012; Portt et al., 2011; Yang et al., 2012). The HSPs are a group of stress proteins which can be classified according to their molecular weight into several sub-families: HSP110, HSP90, HSP70, HSP60, and the small HSPs (Goloudina et al., 2012).

Members of the HSP90 sub-family have been extensively studied and a large number of drugs based on heat shock protein 90 (Hsp90) inhibition are now in preclinical and clinical development for treatment of cancer (Biamonte et al., 2010; Travers et al., 2012). A number of studies, stimulated by an increasing interest in the use of natural compounds for anticancer treatment, have determined

Abbreviations: HSP, heat shock protein family; Hsp, heat shock protein; RNAi, RNA interference; siRNA, small interfering RNA.

* Corresponding author.

E-mail address: dusica.maysinger@mcgill.ca (D. Maysinger). that many of them are Hsp90 inhibitors (Janin, 2010). Celastrol, a compound extracted from the root bark of Trypterygium wilfordii, was found to down-regulate Hsp90s' ability to bind ATP and to disrupt the interaction of Hsp90 with co-chaperone Cdc37 (Peng et al., 2010). Given Hsp90's ability to provide protection against cell death in tumor cells (Whitesell and Lindquist, 2005), celastrol's ability to disturb this chaperon function was considered as a likely explanation of why celastrol could be beneficial in anticancer treatment. However, Hsp90 inhibition was found to subsequently upregulate the expression of the members of another HSP protein sub-family, HSP70 (Mou et al., 2011). This proved to be unfortunate. The HSP70 sub-family, which consists of at least 13 different members, is one of the largest HSP sub-families, and its members have been found to promote cancer cell growth by providing protection against both extrinsic and intrinsic apoptotic stimuli (Beere, 2005; Gotoh et al., 2004). Moreover, in RNA interference (RNAi) studies of human cancer cells of various origin, depletion of Hsc70 (the major constitutively expressed protein of the HSP70 family) and of inducible Hsp70 (the major inducible protein of the HSP70 family, also known as Hsp72 or HSPA1A), increased the extent of apoptosis compared to the apoptosis depletion of these proteins caused in healthy cells of equivalent origin (Powers et al., 2008).

To study the function of antiapoptotic proteins with RNAi, liposome based delivery systems have been mainly used. With the progress of nanotechnology, the approaches to creating 
particles appropriate for entrapping siRNA began to take account of non-lipid polymers, including chitosan (Malmo et al., 2012). Chitosan, made from the chitin of marine anthropods and insects, is a linear, random copolymer of D-glucosamines (deacetylated units) and $\mathrm{N}$-acetyl-D-glucosamines (acetylated units) linked through glycosidic bonds (Baldrick, 2010; Tan et al., 2009; Zhang et al., 2010). The stability of chitosan-based delivery systems is ensured by strong electrostatic interactions between highly positively charged chitosan amino groups and negatively charged nucleotides (Bhattarai et al., 2010; Katas and Alpar, 2006; Malmo et al., 2012). More importantly, chitosan was reported as non-toxic, biocompatible, biodegradable (Baldrick, 2010) and due to its muco-adhesiveness (de la Fuente et al., 2010), appropriate for nonparenteral administration (de Jesús Valle et al., 2008).

The objective of the present study was to incorporate Hsp70 siRNA into chitosan-TPP nanocarriers and to test the efficiency of this system in Hsp70 silencing. Following reduction in Hsp70 expression, the antiproliferative effects of Hsp70 silencing in the presence or absence of the Hsp90 inhibitor, celastrol, were explored. In order to test how effectively the simultaneous inhibition of Hsp70 and Hsp90 acted as a general treatment approach for different human tumors, in this study we used tumor cells originating from the blood and from the brain. In order to take into account the complexity of three dimensional growth of tumors in vivo, Hsp70/ Hsp90 inhibition was also tested in human glioblastoma spheroids.

\section{Materials and methods}

\subsection{Materials}

Ultrapure chitosan glutamate (Protasan UP G113) with approximate molecular weight $<200 \mathrm{kDa}$ and $75-90 \%$ deacetylation was purchased from NovaMatrix (Sandvika, Norway). Celastrol was purchased from PI\&PI Technologies Inc. (Taihe, Baiyun, China). All cell culture media and reagents were purchased from Life Technologies Inc. (ON, Canada). All other reagents were purchased from Sigma Aldrich (ON, Canada), unless stated otherwise.

\subsection{Chitosan-TPP-siRNA nanoparticles preparation}

Chitosan-TPP nanoparticles were produced based on modified protocol for ionic gelation of tripolyphosphate (TPP) with chitosan glutamate described elsewhere (Katas and Alpar, 2006). Briefly, for the association of small interfering RNA (siRNA) with the chitosan and TPP, $15 \mu \mathrm{l}$ of siRNA $(1.33 \mu \mathrm{g} / \mu \mathrm{l})$ in double distilled water was added to the TPP solution $(0.2 \mathrm{ml}, 0.84 \mathrm{mg} / \mathrm{ml}$, sterilized through $0.45 \mu \mathrm{m}$ filter) before adding this drop-wise to the chitosan solution $(0.5 \mathrm{ml}, 2 \mathrm{mg} / \mathrm{ml}$ prepared in $0.1 \mathrm{M}$ sodium acetate buffer, $\mathrm{pH}$ 4.5) under constant magnetic stirring at room temperature. Nanoparticles were spontaneously obtained during stirring and were incubated at room temperature for $30 \mathrm{~min}$ before further analysis or cell transfection.

\subsection{Physical characterization of chitosan-TPP-siRNA nanoparticles: particle size, polydispersity index and zeta potential}

The average particle size and size distribution (polydispersity index) was determined by photon correlation spectroscopy (Zetasizer 3000 HS, Malvern Instruments, Malvern, UK). Measurements were performed at a scattering angle of $90^{\circ}$ and at a temperature of $25{ }^{\circ} \mathrm{C}$. The hydrodynamic diameter was calculated from the autocorrelation function of the intensity of light scattered from particles with the assumption that the particles had a spherical shape. The zeta potential was obtained by laser Doppler anemometry using a Zetasizer 3000 HS. For the measurements, samples were diluted with $10 \mathrm{mM} \mathrm{NaCl}$ solution and placed in an electrophoretic cell, where a potential of $150 \mathrm{mV}$ was established.

\subsection{Asymmetrical flow field-flow fractionation (AF4) for characterization of chitosan-TPP-siRNA nanoparticles}

Asymmetric flow field-flow fractionation was performed using an AF4 system (AFx2000MT, Postnova Analytics, Landsberg, Germany) combined with an UV/Vis detector (SPD-20A, Postnova Analytics) for a set wavelength of $260 \mathrm{~nm}$, a multiangle light scattering detector (MALS, Dawn 8+, Wyatt Technology), and a dynamic light scattering detector (Wyatt-QELS, Wyatt Technology). The scattering angle was kept at $106^{\circ}$. Complete principle of AF4 has been described elsewhere (Yohannes et al., 2011). Data collection and analysis were done using ASTRA version 5.3.4.20 (Wyatt Technology).

\subsection{Determination of siRNA loading efficiency}

The loading efficiency (LE) of siRNA entrapped into chitosanTPP nanoparticles was calculated based on the absorbance (at $260 \mathrm{~nm}$ ) of the free siRNA in the supernatant obtained after particle centrifugation $(13000 \mathrm{~g}, 15 \mathrm{~min})$. Supernatant recovered from unloaded chitosan-TPP nanoparticles (without siRNA) was used as a blank. LE (\%) was calculated according to the following formula:

$\mathrm{LE}(\%)=[($ total siRNA - free siRNA $) /$ total siRNA $] \times 100$

\subsection{Cell cultures and materials}

Human leukemia cells (Jurkat, ATCC) and human breast carcinoma cell line (MCF7, ATCC) were cultured in RPMI 1640 medium containing $10 \%$ foetal bovine serum (FBS) and $1 \%$ penicillin-streptomycin (PS), while human glioblastoma cells (U251N, ATCC) and human hepatocellular carcinoma (HepG2, ATCC) were cultured in DMEM medium containing 10\% FBS and 1\% PS. During treatment and growth cells were maintained at $37{ }^{\circ} \mathrm{C}$ and $5 \% \mathrm{CO}_{2}$ in a humidified atmosphere.

\subsection{Cell transfection and Hsp70 silencing}

Cells were seeded $24 \mathrm{~h}$ prior to transfection in 96-well, 24-well or 6-well plates (Sarstedt) depending on the assay to be performed. For transfection cells were incubated with chitosan-TPP-siRNA nanoparticles in complete growth media at $37{ }^{\circ} \mathrm{C}$ and $5 \% \mathrm{CO}_{2}$ for indicated period of time. Cells treated with "empty" chitosan-TPP nanocarriers, were used as negative control. siRNA incorporated in HiPerFect (Qiagen) and HiPerFect alone were used for comparison with chitosan-TPP nanocarrier. Transfection of siRNA incorporated into HiPerFect was performed according to the manufacturer's protocol. siRNA designed for targeting mRNA transcribed from human hsp70-1 gene (NCBI reference sequence: NM_005345.5) with a sense sequence 5'-CGG UUU CUA CAU GCA GAG Att-3' (siRNA ID: s6966, Life Technologies Inc.) and siRNA of scrambled sequence (Life Technologies Inc.) with no homology to any known human gene (confirmed by conducting NCBI BLAST query) were used.

\subsection{Cell viability}

Three different approaches were used to determine cell viability: (i) cell counting using trypan blue, (ii) labelling nuclei with Hoechst 33342 (fluorescent microscopy) and (iii) determination of mitochondrial metabolic activity (MTT). Cell viability was calculated as a percentage relative to the viability of cells incubated in 
growth media supplemented with 10\% FBS and 1\% PS during the period 1-3 days (i.e. untreated control).

For labelling with trypan blue dye U251N or Jurkat cells were seeded in 96 -well culture plates $\left(1 \times 10^{4}\right.$ cells/well $) 24 \mathrm{~h}$ prior to treatment. The trypan blue dye exclusion assay for cell counting was performed by mixing $80 \mu \mathrm{l}$ of cell suspension with $20 \mu \mathrm{l}$ of trypan blue dye (Life Technologies Inc.) before injecting into a Neubauer counting chamber. The numbers of cells that absorbed the dye (dead cells) and those that excluded the dye (viable cells) were counted, from which the viability in percentages relative to the untreated control was calculated.

For labelling nuclei with Hoechst 33342 U251N or Jurkat cells were seeded in 24 -well culture plates $\left(5 \times 10^{4}\right.$ cells/well) $24 \mathrm{~h}$ prior to treatment. After treatment, media was removed, cells were washed $3 \times$ with $1 \times$ PBS and fixed with $4 \%$ p-formaldehyde (PFA) in $1 \times$ PBS during $10 \mathrm{~min}$. After fixation, cells were washed $3 \times$ with $1 \times$ PBS and incubated with Hoechst $33342(10 \mu \mathrm{M}$ in $1 \times$ PBS $)$ for $10 \mathrm{~min}$ at room temperature. After staining with Hoechst 33342 , cells were washed $3 \times$ with $1 \times$ PBS, and subjected to fluorescent microscopy analysis. Images were acquired with a Leica DFC350FX monochrome digital camera connected to a Leica DMI4000B inverted fluorescence microscope using Leica Application Suite V4. Images were analayzed with Image $\mathrm{J}$ software for the number of nuclei stained with Hoechst 33342 and results were expressed as percentages of the number of nuclei stained with Hoechst 33342 in untreated control.

A colorimetric MTT assays was performed to assess the activity of living cells via mitochondrial dehydrogenases. Mitochondrial dehydrogenases of viable cells cleave the tetrazolium ring, yielding purple formazan crystals. For MTT assay cells were seeded in 24-well cell culture plates $\left(5 \times 10^{4}\right.$ cells/well for U251N; $1 \times 10^{5}$ cells/well for Jurkat) $24 \mathrm{~h}$ prior to treatment. Cells were treated for $24 \mathrm{~h}$ or up to 5 days (as indicated in figures). At the end of treatments cells were incubated with MTT solution $(0.5 \mathrm{mg} / \mathrm{mL})$ for $1 \mathrm{~h}$ at $37^{\circ} \mathrm{C}$, after which medium was removed and DMSO was added to lyse cells, and dissolve the formazan product. Absorbance was measured at $595 \mathrm{~nm}$ using a Benchmark microplate reader (Bio-Rad, Mississauga, ON, Canada). The extent of formazan conversion was expressed in percentages relative to the untreated control. All measurements were done in triplicates in three or more independent experiments.

\subsection{Quantitative real time-polymerase chain reaction ( $q R T-P C R$ ) for the analysis of transfection efficiency}

All reagents used for qRT-PCR were purchased from Life Technologies Inc. For qRT-PCR Jurkat cells were seeded in 24-well cell culture plates $\left(1 \times 10^{5}\right.$ cells/well $)$ and treated with chitosan-TPPsiRNA nanoparticles for $24 \mathrm{~h}$. HiPerFect transfection reagent (Qiagen) was used as a positive control for Hsp70 siRNA delivery into the cells. At the end of treatments total cellular RNA was extracted using phenol free method (RNAqueous-4PCR Kit) according to the manufacturer's protocol. Isolated RNA $(0.2 \mu \mathrm{g})$ was reversely transcribed using the High Capacity cDNA reverse transcription kit. Gene expression levels were measured by quantitative real-time PCR on AB7500 real-time PCR system (Applied Biosystems, USA) with gene expression TaqMan master mix and TaqMan genotyping Assay for inducible Hsp70 (Hs00359147_s1) and for GAPDH as a housekeeping gene control (Hs99999905_m1). All kits and reagents were used according to manufacturer's protocols. Data were collected and analysed with 7500 System SDS software v1.4 21.

\subsection{U251N spheroids preparation}

Human glioblastoma tumor spheroids were prepared according to Friedrich et al. (2009). Briefly, 2\% agarose solution (in serum free
DMEM) was autoclaved for $20 \mathrm{~min}$ at $120^{\circ} \mathrm{C}$. Flat bottomed $96-$ well plates were coated with $75 \mu \mathrm{L} /$ well of agarose solution to produce concave non-adherent surface area in wells. Agarose coated plates were used for growth of tumor spheroids based on liquid overlay technique (Carlsson and Yuhas, 1984). Exponentially growing monolayer U251 $\mathrm{N}$ cells were trypsinized and $5 \times 10^{3}$ cells were seeded per well in $200 \mu \mathrm{L}$ of DMEM supplemented with $10 \%$ FBS and $1 \%$ PS. Subsequently, plates were gently agitated for $5 \mathrm{~min}$, and then transferred at $37^{\circ} \mathrm{C}$ in a humidified atmosphere. $50 \%$ of the media in the wells was replaced every 2 days with fresh complete media. Spheroids were treated with siRNA incorporated in chitosan-TPP or Lipofectamine 2000 (Invitrogen) or with with siRNA incorporated in one of the nanocarriers accompanied with celastrol treatment 4 days after seeding, for $48 \mathrm{~h}$. Only spheroids of spherical shape were used for treatments ( 4 spheroids per condition) and each experiment was repeated 3 times $(n=12)$.

\subsection{Cell viability in U251N spheroids}

Hoechst 33342 staining and propidium iodide (PI) staining were performed to observe the integrity and viability of U251N spheroids after treatment with celastrol and/or chitosan-TPP nanoparticles. Hoechst 33342 is membrane permeable dye and specifically stains the nuclei of viable cells by binding into the minor groove of DNA. Unlike Hoechst 33342, PI is membrane impermeable dye and specifically stains DNA of the cells with damaged plasma membranes.

Tumor spheroids prepared from $5 \times 10^{3} \mathrm{U} 251 \mathrm{~N}$ cells (Human glioblastoma) were treated for $48 \mathrm{~h}, 4$ days after seeding, as described in previous section. At the end of treatment 50\% $(100 \mu \mathrm{l})$ of the media was replaced with media containing Hoechst 33342 (for $10 \mu \mathrm{M}$ final concentration) and PI (for $1.5 \mu \mathrm{M}$ final concentration), and the spheroids were incubated for the next $2 \mathrm{~h}$ at $37^{\circ} \mathrm{C}$ in a humidified atmosphere before fluorescent microscopy analysis. Images were acquired with a Leica DFC350FX monochrome digital camera connected to a Leica DMI4000B inverted fluorescence microscope using Leica Application Suite V4. Image analysis (relative fluorescence intensity measurements) was performed using Image J software.

\section{Results}

\subsection{Chitosan, TPP and siRNA form nanoparticles}

Chitosan nanoparticles formed spontaneously due to the electrostatic interactions between the highly positively charged amino groups of chitosan and the negatively charged phosphate groups of siRNA, and/or phosphate groups of the TPP molecules (Fig. 1A). Chitosan-TPP nanoparticles with or without siRNA were similar in size (approximately $200 \mathrm{~nm}$, as measured by photon correlation spectroscopy, Table 1 ). Their polydispersity indices were comparable $(\sim 0.500)$. Chitosan-TPP-siRNA nanoparticles displayed a positive surface charge ( $\zeta$-potential) in the range $+32.7 \pm 0.7 \mathrm{mV}$ at $\mathrm{pH} 4.5$ and $+22.8 \pm 2.2 \mathrm{mV}$ at $\mathrm{pH} 7.4$. Additional analysis of nanoparticle size distribution was done using two different media, acetate buffer at $\mathrm{pH} 4.5$, and phosphate-buffered saline (PBS) at $\mathrm{pH}$ 7.4, using asymmetric flow field-flow fractionation (AF4/UV/ MALS). Fig. 1B shows a size distribution between $100 \mathrm{~nm}$ and $200 \mathrm{~nm}$ for nanoparticles analysed at $\mathrm{pH} 4.5$. A broader, bimodal size distribution of chitosan-TPP-siRNA particles was observed at $\mathrm{pH} 7.4$; one peak centered around $100 \mathrm{~nm}$ and another peak around $500 \mathrm{~nm}$. (Supplementary Fig. 1A). The elution peak appeared in less than $10 \mathrm{~min}$ (Fig. 1B), indicating a large portion of free siRNA and loading efficiency of about $50 \%$. This result was comparable to the data obtained from the measurements of 
A

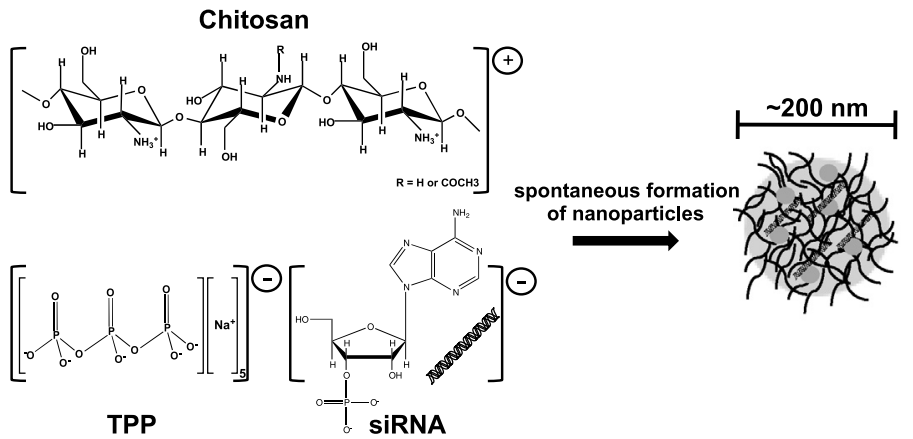

C

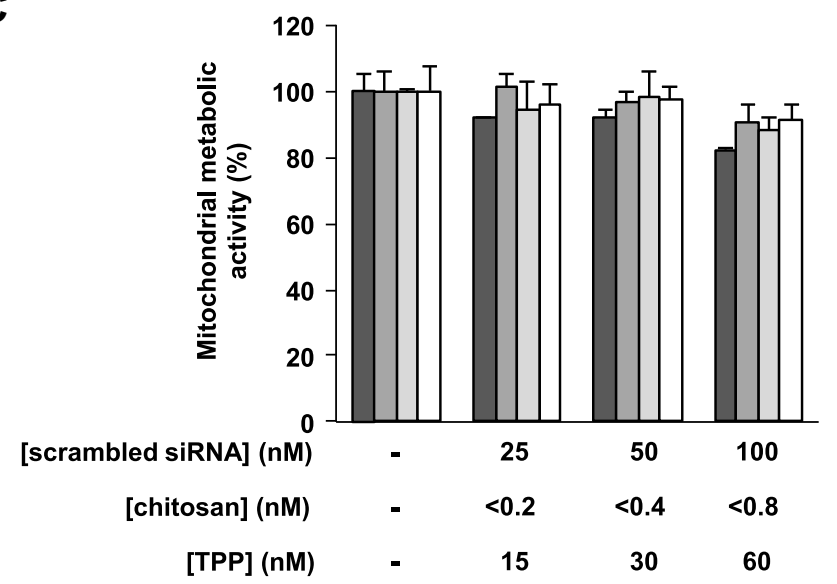

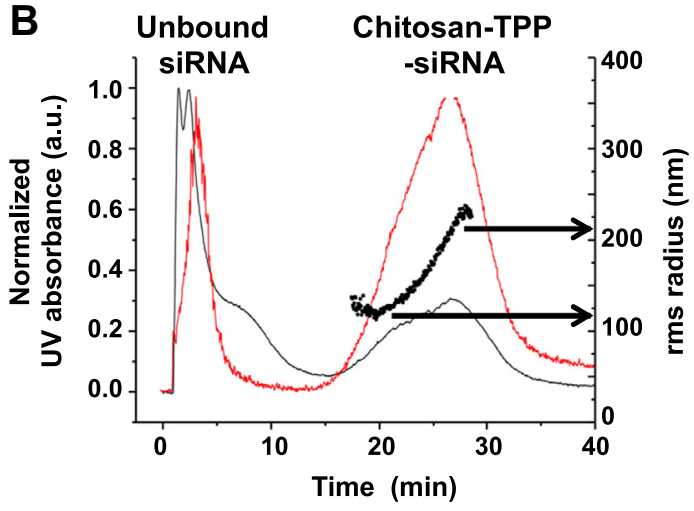

D

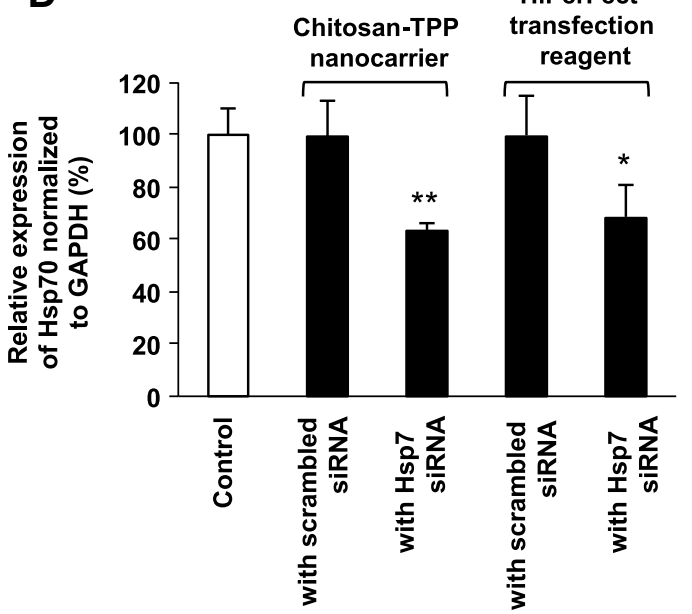

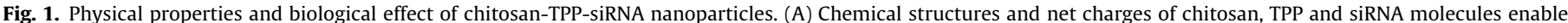

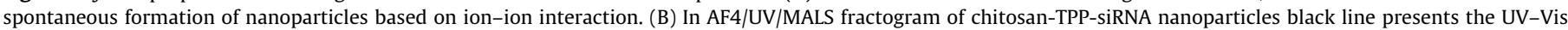

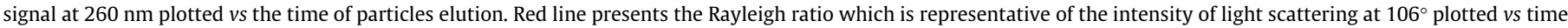

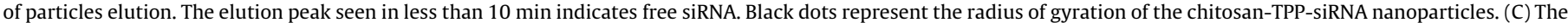

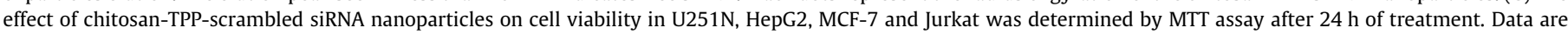

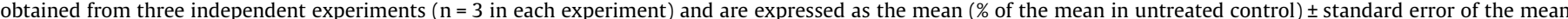

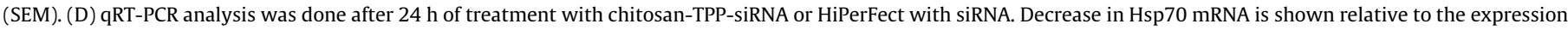
of GAPDH mRNA. Results are expressed as the mean (\% of the mean in untreated control) \pm SEM $\left(n=3 ;{ }^{*} p<0.05\right.$, ${ }^{* *} p<0.01$ vs untreated control).

Table 1

Particles size, polidispersity index and $\zeta$-potential of chitosan nanoparticles.

\begin{tabular}{|c|c|c|c|c|}
\hline Composition & Size $(\mathrm{nm}) \pm \mathrm{SD}$ & Polidispersity index & $\zeta$-Potential $(\mathrm{mV}) \pm \mathrm{SD}$ in $\mathrm{pH} 4.5$ & $\zeta$-Potential $(\mathrm{mV}) \pm \mathrm{SD}$ in $\mathrm{pH} 7.4$ \\
\hline Chitosan-TPP & $219.1 \pm 4.3$ & 0.543 & $+32.7 \pm 0.7$ & $+20.8 \pm 2.7$ \\
\hline Chitosan-TPP-siRNA & $197.8 \pm 4.3$ & 0.454 & $+33.71 \pm 0.7$ & $+22.8 \pm 2.2$ \\
\hline
\end{tabular}

absorbance at $260 \mathrm{~nm}$. Free siRNA in the medium did not significantly alter the size distribution of chitosan-TPP-siRNA nanoparticles up to 4 days (Supplementary Fig. 1B). Toxicity of naked siRNA (10-100 nM) was non-significant (Supplementary Fig. 1C).

\subsection{Chitosan-TPP nanocarriers with scrambled siRNA show low toxicity in different tumor cell lines}

Chitosan and its derivatives are generally less toxic than other cationic polymers in cell cultures. Here we investigated cytotoxicity of chitosan-TPP nanocarrier with scrambled siRNA included. Treatment of four different cell lines (U251N, HepG2, MCF-7 and Jurkat cells) with the nanocarriers containing scrambled siRNA at a concentration of $25 \mathrm{nM}$ or $50 \mathrm{nM}$ caused neither a decrease in mitochondrial metabolic activity (Fig. 1. C) nor a significant reduction in cell number within $24 \mathrm{~h}$ (data not shown). However, chitosan-TPP nanocarriers with scrambled siRNA at a concentration of
$100 \mathrm{nM}$ caused a significant decrease in U251N cell viability $(82 \pm 0.8 \%, p<0.05)$. These results suggest that chitosan-TPP nanocarriers are only suitable as vehicles for siRNA within a limited concentration range.

\subsection{Chitosan-TPP-Hsp70 siRNA nanoparticles efficiently knock-down inducible Hsp70 expression}

qRT-PCR was used to measure the effect of Hsp70 siRNA ( $50 \mathrm{nM}$ ) in chitosan-TPP nanoparticles on Hsp70 expression in Jurkat cells (Fig. 1D). Hsp70 mRNA concentration was decreased to $63 \%( \pm 3.1 \%)$ relative to the concentrations in untreated control cells after $24 \mathrm{~h}$ of incubation. This decrease was comparable to that obtained by transfection with commercially available lipid based transfection reagent, HiPerFect $(68 \pm 12.1 \%)$. Thus, despite the broad size distribution and relative instability of chitosan-TPP-siRNA nanoparticles at 7.4, their silencing of Hsp70 was significant. 
In addition to the evidence for the lack of toxicity of chitosanTPP nanocarriers we wanted to establish that the silencing of Hsp70 by chitosan-TPP-siRNA nanoparticles was not due to the carrier component itself. We therefore measured the expression of Hsp70 in Jurkat cells exposed to chitosan-TPP or to scrambled siRNA, and found no significant change in Hsp70 levels, both the gene and the protein, after 24 or $48 \mathrm{~h}$ (Supplementary Fig. 2). We conclude that a decrease in the expression of Hsp70 mRNA is specific to chitosan-TPP-Hsp70 siRNA treatment because neither the carrier alone nor scrambled siRNA were able to silence the gene.

\subsection{Chitosan-TPP-Hsp70 siRNA nanoparticles induce cell death}

Induction of cell death was studied in U251N or Jurkat cells following Hsp70 silencing with Hsp70 siRNA ( $50 \mathrm{nM}$ ) in chitosan-TPP nanocarriers. A repeated treatment (every $24 \mathrm{~h}$ ) with chitosan-TPPHsp70 siRNA lead to a significant decrease $(50 \pm 0.22 \%, p<0.001)$ in U251N cell viability after 2 days (Fig. $2 \mathrm{~A}$ ) compared to treatment with scrambled siRNA in chitosan-TPP nanoparticles, chitosanTPP nanoparticles alone or untreated control. Similarly, a significant decrease in Jurkat cell viability was observed after 3 days $(70 \pm 4.5 \%, p<0.001)$ compared to treatment with scrambled siRNA in chitosan-TPP nanoparticles, chitosan-TPP nanoparticles alone or untreated control (Fig. 2B). Treatment with chitosan-TPP-scrambled siRNA nanoparticles lead to minor but significant decrease in viability of $U 251 \mathrm{~N}$ cells after 2 days ( $81 \pm 0.4 \%, p<0.05$ ), implicating sensitivity of this cell line to the repeated (after $48 \mathrm{~h}$ ) but not single (after $24 \mathrm{~h}$ ) treatment with chitosan-TPP nanocarriers. The marked reduction in cell viability implicated inducible Hsp70 involvement in the sustaining of signalling pathways contributing to the cell proliferation in these two tumor cell lines.

\subsection{Hsp70 siRNA enhances tumor cell death caused by celastrol}

Celastrol (Fig. 3A) was previously shown to cause reduction in cell viability in glioma and leukemia cells, (Ge et al., 2010; Peng et al., 2010). We observed a concentration dependent reduction in both mitochondrial metabolic activity and cell number in human glioblastoma (U251N) and in leukemia cells (Jurkat) after $24 \mathrm{~h}$ exposure to celastrol (Fig. 3B). Since celastrol ( $\geqslant 1 \mu \mathrm{M}$ ) increased the expression of inducible Hsp70 in human cervical carcinoma cells (HeLa) and in human neuroblastoma cells (SH-SY5Y) as implied by (Westerheide et al., 2004), we hypothesized that the combination of Hsp70 silencing by siRNA and treatment with celastrol would lead to either an additive or a synergistic cell death. We found a significant reduction in cell viability of U251N when celastrol $(1 \mu \mathrm{M})$ treatment was combined with chitosanTPP-Hsp70 siRNA based inducible Hsp70 silencing ( $73 \pm 9.8 \%$, $p<0.05$, Fig. $4 \mathrm{~A}$ ) for $24 \mathrm{~h}$. Celastrol treatment alone, celastrol combined with chitosan-TPP or celastrol combined with scrambled
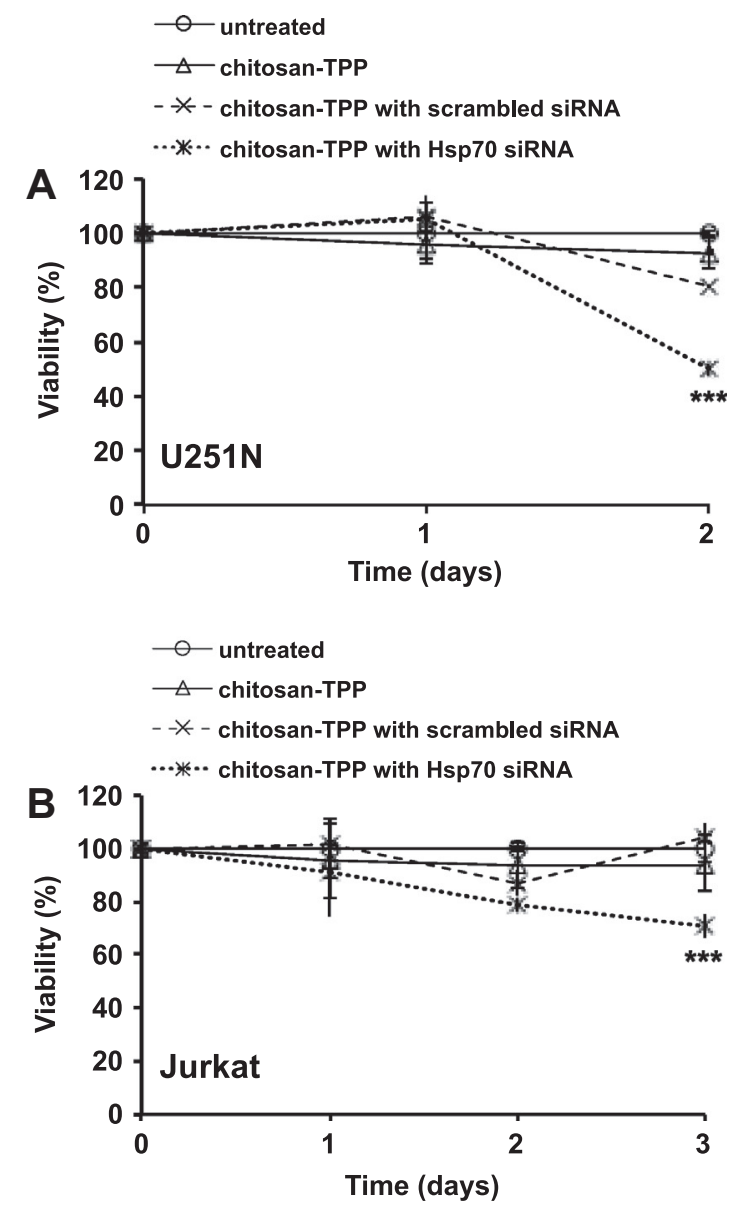

Fig. 2. Induction of cell death following Hsp70 silencing. Hsp70 silencing with Hsp70 siRNA ( $50 \mathrm{nM}$ ) incorporated in chitosan-TPP nanoparticles caused a significant reduction in cell viability after 2 days in U251N (A) or 3 days in Jurkat cells (B). Cell viability was determined using trypan blue exclusion assay. Mean values $( \pm$ SEM) are expressed as a percentage (\%) of change from the untreated controls $\left(n=3 ;{ }^{* * *} p<0.001\right)$.

siRNA in chitosan-TPP nanoparticles did not cause any significant U251N cell death. A combination therapy (chitosan-TPP-Hsp70 siRNA and celastrol), however, dramatically decreased Jurkat cell viability after $24 \mathrm{~h}(21 \pm 2.2 \%, p<0.001)$ (Fig. 4B). This decrease in Jurkat cell viability was significantly different from that caused by celastrol treatment alone $(72 \pm 9.9 \%)$, by celastrol treatment combined with scrambled siRNA in chitosan-TPP nanoparticles $(50 \pm 7.8 \%)$ or by celastrol treatment combined with chitosan-TPP (74 $\pm 12.2 \%$ ) suggesting an enhancment of celastrol's cell death promoting activity with this combined intervention.
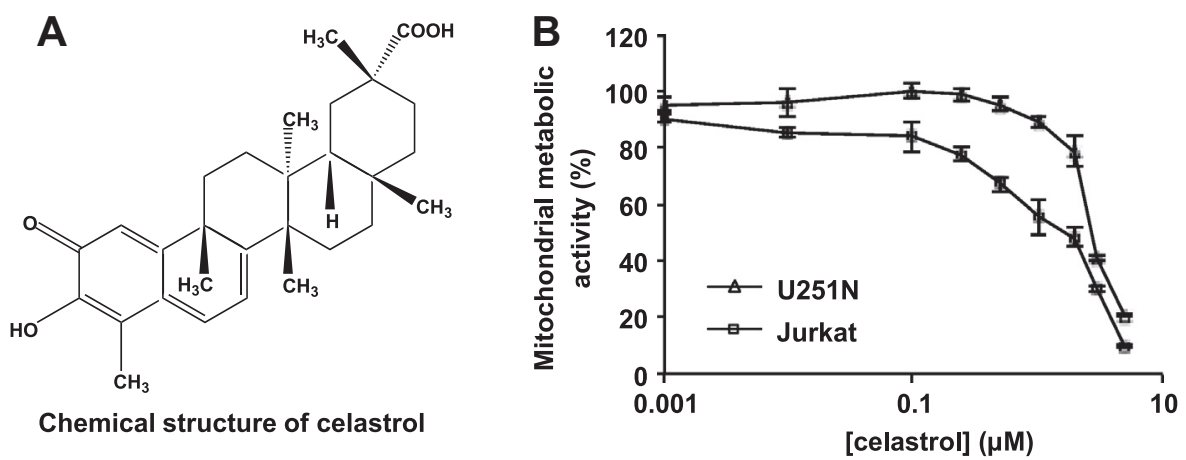

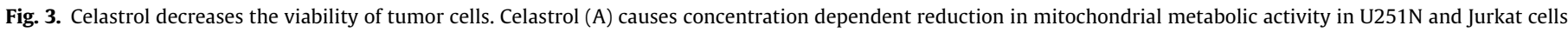
(B) after $24 \mathrm{~h}$. Mean values ( \pm SEM) expressed as a percentage (\%) of change from the untreated controls are shown. 

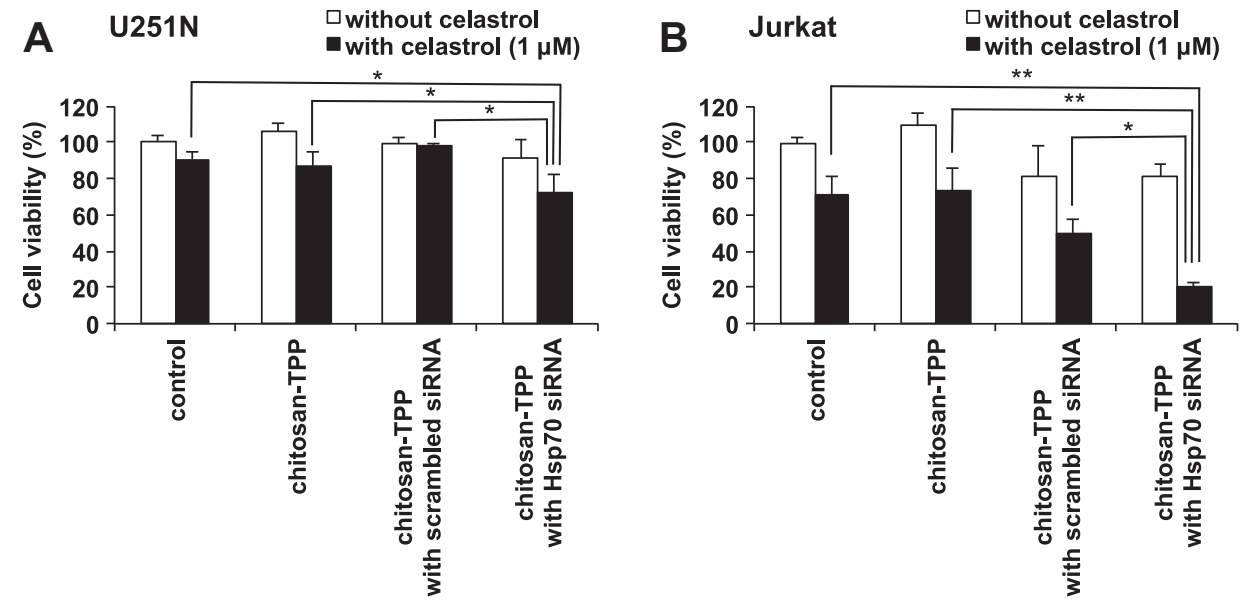

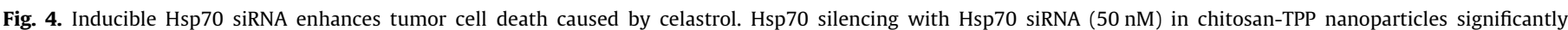

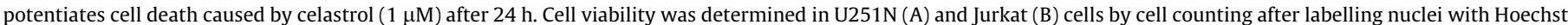
33342. Mean values $\left( \pm\right.$ SEM) are expressed as a percentage $(\%)$ of change from the untreated controls $\left(n=3 ;{ }^{*} p<0.05\right.$, $\left.{ }^{* *} p<0.01\right)$.
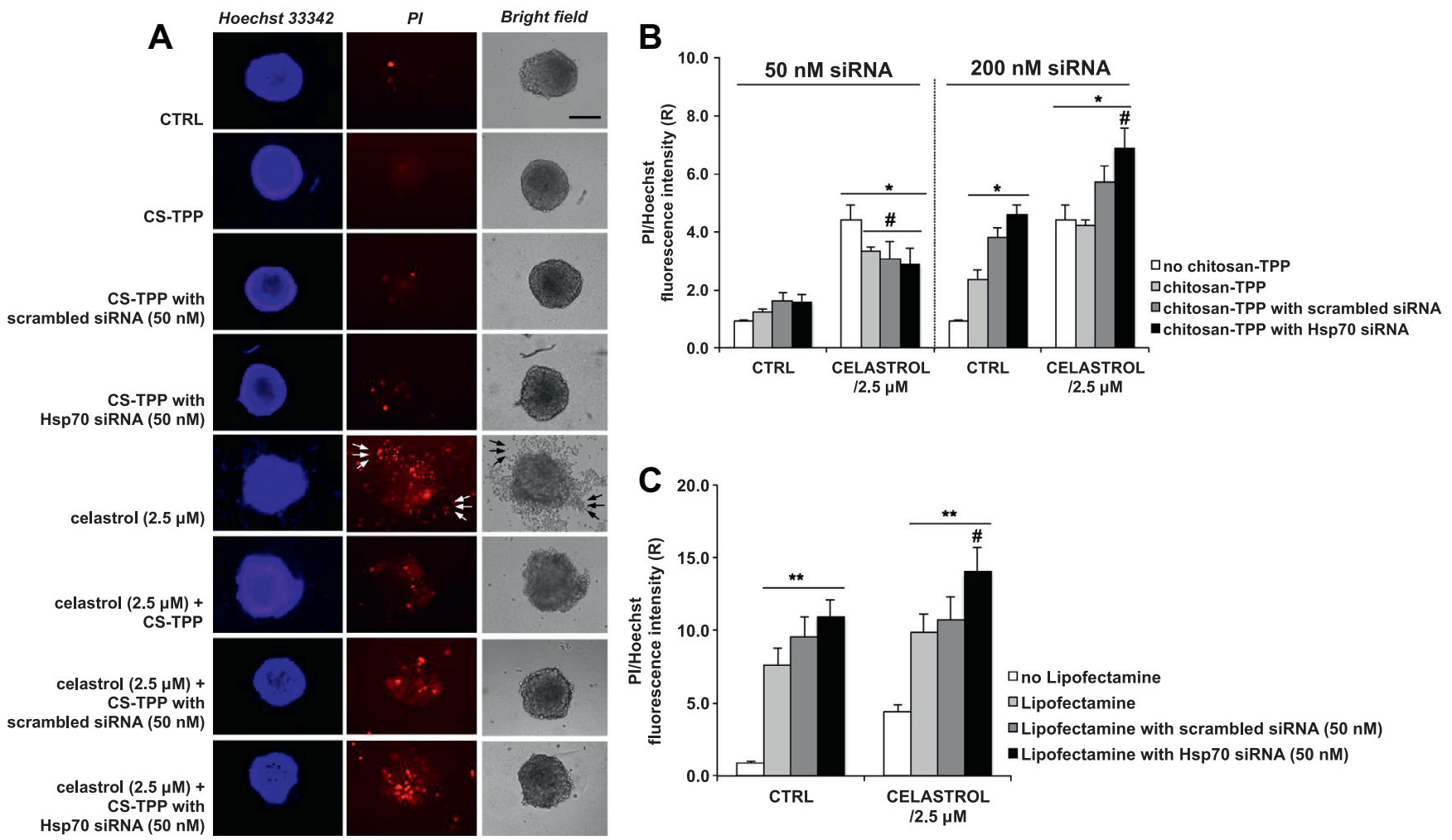

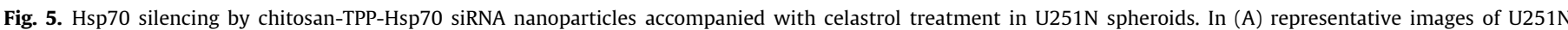

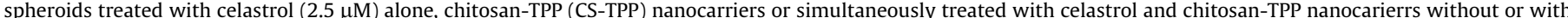

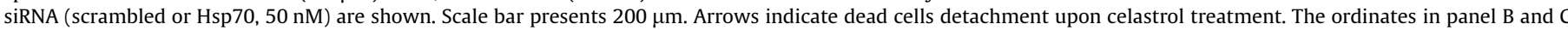

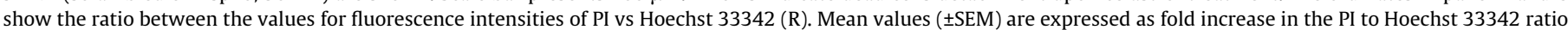
vs ratio in the untreated controls $\left(n=12 ;{ }^{*} p<0.05,{ }^{* *} p<0.01\right.$ compared to untreated controls; ${ }^{\#} p<0.05$, ${ }^{\# \#} p<0.01$ compared to treatment with $2.5 \mu \mathrm{M}$ celastrol alone).

\subsection{Responsiveness of U251N spheroids to combination therapy is limited}

Accessibility of cytotoxic agents into tumor spheroids may be limited by hypoxia and poor vascularisation within the necrotic cores (Mehta et al., 2012). Since protein expression and growth patterns present in tumor spheroids resemble those of the solid tumors in vivo (Onozuka et al., 2011), we opted to test the effectiveness of combination therapy (chitosan-TPP-Hsp70 siRNA and celastrol) in U251N spheroids. Fig. 5A shows the results from fluorescent microscopy and phase contrast imaging of U251N spheroids subjected to treatments with chitosan-TPP nanoparticles and/or celastrol. U251N spheroid size was approximately $400 \mu \mathrm{m}$ in diameter after 4 days. Following celastrol treatment $(\geqslant 2.5 \mu \mathrm{M}$, $48 \mathrm{~h}$ ) cell viability within U251N spheroids was reduced inside the core (40\%). Additionally, dead cells dissociated (indicated by arrows) from the outer proliferation zone, and this resulted with a decreased U251N spheroid sizes. U251N spheroids, however, 
remained intact following combination treatment with celastrol and chitosan-TPP or with celastrol and chitosan-TPP-siRNA (scrambled or Hsp70, $50 \mathrm{nM}$ ). Chitosan-TPP nanocarriers possibly strengthened cell to cell contact thereby preventing penetration of celastrol and thus its activity. Fukuda et al. (2006) showed that cellular attachment properties changed from repulsive to adhesive in the presence of chitosan when tumor spheroids were cultured on photocrosslinkable chitosan hydrogels. It is conceivable that chitosans' adhesive properties played a role in the experiments described here.

To assess the cell death, U251N spheroids were labeled with PI and the total number of nuclei was determined by labelling with Hoechst 33342 fluorescent dye. The ratio (R) between the PI and Hoechst 33342 fluorescence intensities (Fig. 5B), set as 1 in untreated control, was significantly increased $(R=4.4 \pm 0.5, p<0.05)$ with celastrol treatment $(2.5 \mu \mathrm{M})$, compared to untreated control. Compared to celastrol treatment, with combination treatment of Hsp70 siRNA (50 nM) in chitosan-TPP nanocarriers and celastrol, PI to Hoechst ratio was significantly decreased $(R=2.8 \pm 0.5$, $p<0.05)$. Celastrol treatments at concentrations $\leqslant 1 \mu \mathrm{M}$ were ineffective in decreasing the viability of U251N spheroids. The addition of Hsp70 siRNA at a concentration of $50 \mathrm{nM}$ in chitosan-TPP nanoparticles did not produce enhanced effect for celastrol in spheroids as observed in monolayers, suggesting an inadequate access of therapeutic agents into the core of these 3D cell cultures. These results suggest that to induce cell death in U251N spheroids higher concentrations of celastrol and siRNA in chitosan-TPP nanocarriers are necessary than those in U251N monolayers. A viability of U251N spheroids was significantly reduced with combined treatment of celastrol $(2.5 \mu \mathrm{M})$ and Hsp70 siRNA of a higher concentration $(200 \mathrm{nM})$ in chitosan-TPP nanocarriers after $48 \mathrm{~h}(R=6.9 \pm 0.6$, $p<0.05)$. Chitosan-TPP-siRNA nanoparticles themselves were also toxic at this dose $(R=3.6 \pm 1.1$, Fig. $5 \mathrm{~B})$ although to the smaller extent. Treatments with celastrol $(2.5 \mu \mathrm{M})$ and Hsp70 siRNA (50 nM) using lipid based reagent, Lipofectamine 2000 (Invitrogen), also significantly decreased the viability of U251N spheroids $(R=14 \pm 1.7, p<0.05$, Fig. $5 C)$ after 48 h. Although both nanocarriers induced cell death by themselves, chitosan-TPP nanocarriers were significantly less cytotoxic $(R=3.6 \pm 1.1$ in chitosan-TPP treatments, $R=9.4 \pm 1.7$ in Lipofectamine 2000 treatments, $p<0.01$, Supplementary Fig. 3).

\section{Discussion}

Exploiting RNA interference to induce gene silencing has enormous clinical potential for treatment of number of diseases, including cancer (Leung and Whittaker, 2005). In general, RNA interference technology is moving toward the use of non-harmful delivery systems such as exosomes, which are endogenously present in the organism (El Andaloussi et al., 2012; van den Boorn et al., 2011). However, polymer based nanoparticles have shown to be suitable for the delivery of siRNA and have become an exciting field of siRNA delivery research (Zhang et al., 2007). Because of the adhesive properties of chitosan, which facilitate its nonparenteral pulmonary, nasal and oral administration a variety of chitosan nanocarriers have been utilized for the delivery of macromolecules (Csaba et al., 2009; Krauland and Alonso, 2007) and siRNA (Holzerny et al., 2012; Jørgensen et al., 2012). Chitosan modifications have been introduced to increase the efficiency of siRNA intracellular delivery and to reduce toxicity. For example, nonaarginine-modified chitosan (Park et al., 2013), folate-chitosan (Fernandes et al., 2012) and gold nanoparticles-coupled chitosan (Han et al., 2012) were used. In particular, chitosan nanocarriers coupled with TPP have been found to have an excellent transfection efficacy upon in vitro administration (Csaba et al., 2009; Katas and Alpar, 2006; Malmo et al., 2012). The ionotropic gelation between chitosan and oppositely charged polyanions such as TPP has attracted great attention due to the simplicity and mildness of the process. We too did not find significant reduction in cell viability in different tumor cell lines when these were treated with chitosan-TPP nanocarriers. The principal outcome of the present study, however, is the demonstration that chitosan-TPP nanocarriers, which have low toxicity, can be used with advantage as a delivery system for siRNA in vitro, in this instance bringing about a silencing of inducible Hsp70 in tumor cells.

Hsp70 acts as a molecular chaperone in the cells by helping the refolding of misfolded proteins and assisting in their elimination, thereby exibiting its cytoprotective mechanisms However, it is desirable that in tumor cells this protection is not active (Sreedhar and Csermely, 2004). Our studies show that downregulation of Hsp70 in human glioblastoma cells (U251N) and in human leukemia cells (Jurkat) deprives the cells of Hsp70' cytoprotective function, causing deactivation of proliferative signalling pathways and activation of cell death. Previously, it has been shown that specific suppression of Hsp70 with RNA interference can efficiently inhibit the growth of tumor cells in vitro and in vivo (Xiang et al., 2008). However, to our knowledge, chitosan-TPP based delivery systems have not been used before for Hsp70 inhibition in human glioblastoma and in human leukemia cells.

In this study we confirmed the anti-proliferative effects of celastrol in tumor cells already reported (Huang et al., 2008; $\mathrm{Lu}$ et al., 2010). Inhibition of cell proliferation is sufficient to prevent the growth of certain tumor cell types, while in other the combination of drugs that oppose cell proliferation with drugs or factors that interfere with anti-apoptotic mechanisms is necessary in order to stop tumor growth. A lot of effort has gone into identifying the molecular pathways involved in apoptosis in tumor cells and into making the tumor cells more susceptible to therapyinduced apoptosis. However, interventions are complicated by the building up of resistance mechanisms towards therapeutic agents to a threshold that limits therapeutic efficacy. Inducible Hsp70 expression is considered to be one of these resistance mechanisms, and we studied, therefore, if combining celastrol treatment with inducible Hsp70 siRNA would provide a novel antitumor therapy. As an inhibitor of Hsp90, celastrol has been extensively studied, because inhibition of this single protein can cause degradation of multiple oncoproteins (Whitesell and Lindquist, 2005). It is well established that Hsp70 expression is increased following treatment with celastrol in human tumor cell lines (Gabai et al., 2005). It seems clear, therefore, that the activation of prosurvival chaperons like Hsp70 is involved in resistance to drugs based on Hsp90 inhibition and consequently many studies have been exploring the synergism between Hsp70 and Hsp90 inhibitor molecules. In cell culture the combination of 17-allylamino-17-demethoxygeldanmycin (17-AAG) and cisplatin has shown great promise, cisplatin coincidentally strongly suppressing the activation of Hsf-1 (a transcriptional activator of heat shock genes) by 17-AAG (McCollum et al., 2008). These two agents act synergistically, leading to an increased apoptosis as compared to the use of each agent alone. Another small molecule inhibitor, benzylidene lactam compound KNK437 combined with 17-AAG attenuated the 17-AAG-mediated induction of Hsp70 and increased the levels of 17-AAG-induced apoptosis in human AML HL-60 cells (Guo et al., 2005). Findings from these studies provided a proof of concept for the simultaneous targeting of Hsp70 and Hsp90. In the current study we proposed a new approach to antitumor therapy, in this instance based on Hsp70 inhibition with Hsp70 siRNA (in nanocarriers) combined with Hsp90 inhibitor, celastrol (without nanocarrier).

We used the RNAi approach to investigate the effects of specifically silencing the expression of Hsp70 induced by celastrol in two cancer cell lines. The results demonstrate that Hsp70 silencing has 


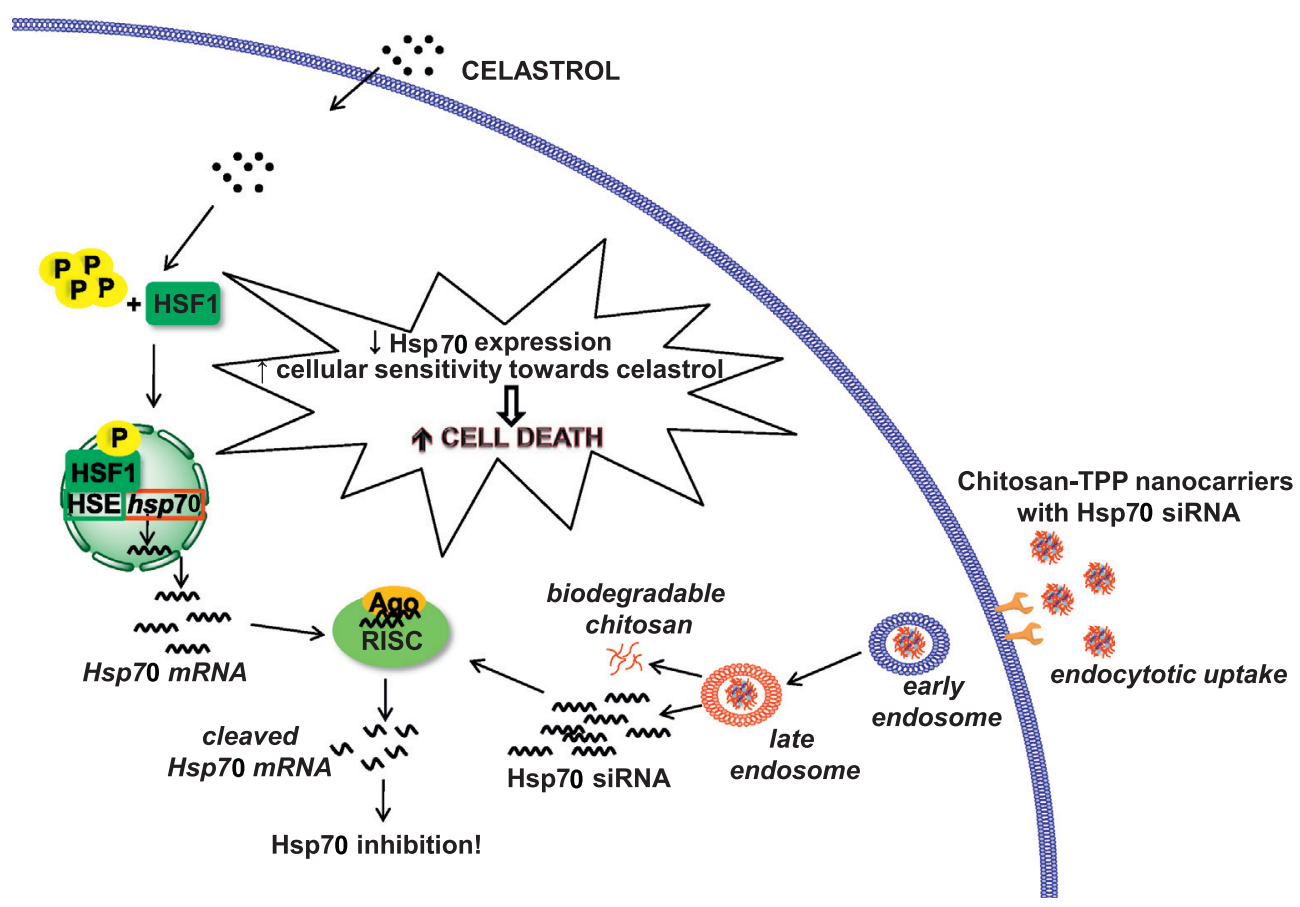

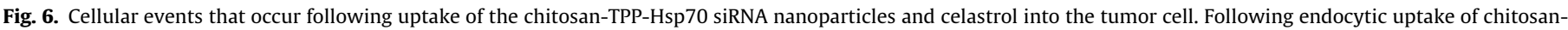

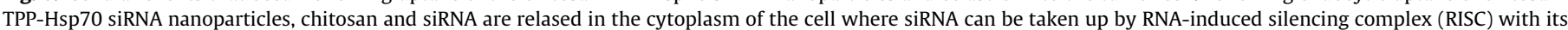

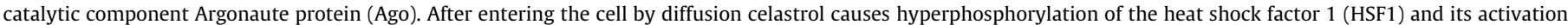

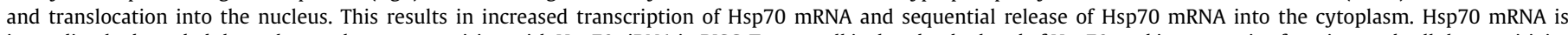

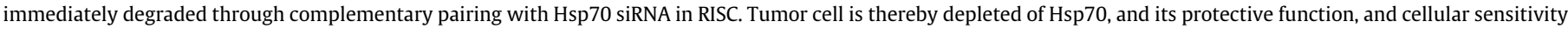
to cell death induced by celastrol is increased.

significant effect on the anti-proliferative function of celastrol in both tumor cell lines. Accordingly, we proposed a combination of Hsp90 and Hsp70 inhibitors as a potential antitumor therapy (Fig. 6). As mentioned earlier, an important consequence of celastrol treatment is the induction of heat shock protein 70 gene expression by activation of Hsf1 (Westerheide et al., 2004). Its activation occurs by phosphorylation; this is followed by its translocation to the nucleus and binding to heat shock elements (HSE), promoters of the heat shock genes. The result is an increased transcription of Hsp70 mRNA and its sequential translation into Hsp70. The objective here was to achieve an inhibition of Hsp70 expression by Hsp70 siRNA simultaneously delivered into the cell with celastrol. If the expression of Hsp70 is diminished in cancer cells, its protective function is also removed, and those cells become more sensitive to celastrol. The result is a greater level of cell death than would have been caused by celastrol treatment alone. These findings also suggest that the effectiveness of other Hsp90 inhibitors could be increased if an equivalent sequence of events was initiated.

In this study we explored the effectiveness of a proposed combination antitumor therapy in U251N spheroids. Tumor spheroids have been used for screening of several anticancer agents and their preparation and properties have been previously discussed (Friedrich et al., 2009; Hirschhaeuser et al., 2010; Ivascu and Kubbies, 2006; Khaitan et al., 2006; Mehta et al., 2012). Nowadays it is considered a prerequisite to study the effectiveness of any proposed antitumor therapeutic in 3D tumor models after carrying out the study in 2D tumor models (cells grown in monolayers) and before conducting in vivo study. Here we show that the adhesive properties of chitosan, in tissue engineering usually considered a positive property (Kim et al., 2008), in tumor spheroids enhanced cell to cell contacts as proliferation progressed. Tumor cells detached from the spheroid when celastrol treatment was applied alone, but cell to cell interactions were preserved in combination therapy treatment decreasing the anti-proliferative effect of celastrol. We propose that chitosan molecules from chitosan-TPP-Hsp70 siRNA nanoparticles preserve cell to cell interactions in the proliferation zone, consequently reducing gene silencing activity of the Hsp70 siRNA. These speculations are in accordance with the work of Yeh et al. (2012), who were able to generate stem cell spheroids on chitosan membranes. That group exploited chitosan membranes as a calcium reservoir and showed that the expression of $\mathrm{N}$-cadherins, molecules involved in cell-cell interaction and adhesion in spheroids, was dependent on available calcium from these membranes. Chitosan and chitosan derivatives have been widely used as dressing materials for wound healing (Jayakumar et al., 2011). The same principle applies to the application of chitosan to a wound site, which leads to coating of the wound by extracellular matrix proteins (ECM), which themselves mediate subsequent cellular interactions, cell adhesion, and cell aggregation (Lord et al., 2011). It seems likely, therefore, that chitosan also modulates cell adhesion in U251N spheroids by activating comparable cellular events. It would seem that chitosan based nanocarriers are likely to consolidate cell to cell interaction of solid tumors in vivo. If so, chitosan-TPP nanocarriers would not only prove themselves to be inefficient in their siRNA delivery function, but would also be responsible for maintaining tumor activity in vivo. Chitosan is an interesting material but it requires significant chemical modifications for realistic clinical applications. In our studies only one modification was introduced, but further modifications will be necessary to make this attractive biomaterial suitable for eventual siRNA delivery in humans. So far the most promising carrier for siRNA was shown to be PEG coated cyclodextrin-based polymer, currently in clinical trials for treatment of solid tumors (Davis et al., 2010). Possible clinical applications of chitosan nanocarriers on the other hand were suggested for nerve repair after spinal cord injury (Mittnacht et al., 2010). 
In conclusion, although chitosan based nanomedicines show great biocompatibility, low toxicity, satisfactory siRNA encapsulation and delivery efficiency in nonparenteral application routes, more research into the adhesive properties of chitosan needs to be done before these delivery systems for siRNA and drug delivery in vivo can be fully exploited.

\section{Acknowledgements}

This work was supported by the Ministry of Science, Education and Sports of the Republic of Croatia (Project Number: 0060061117-1236), Canadian Institute for Health Research (CIHR; MOP 89995, MOP 119425) and European Molecular Biology Organization (EMBO Short-Term Fellowships Programme). We would like to thank the Department of Chemistry at University of Montreal (QC, Canada) and Alexandre Moquin for their help with nanoparticles characterization. Special acknowledgement to Dr. Jack Diamond for his critical appraisal of the text. We would also like to thank Yiming Cui for his help with cell viability experiments.

\section{Appendix A. Supplementary material}

Supplementary data associated with this article can be found, in the online version, at http://dx.doi.org/10.1016/j.ejps.2013.04.001.

\section{Referances}

Baldrick, P., 2010. The safety of chitosan as a pharmaceutical excipient. Regul. Toxicol. Pharmacol. 56, 290-299.

Beere, H.M., 2005. Death versus survival: functional interaction between the apoptotic and stress-inducible heat shock protein pathways. J. Clin. Invest. 115, 2633-2639.

Beere, H.M., Wolf, B.B., Cain, K., Mosser, D.D., Mahboubi, A., Kuwana, T., Tailor, P., Morimoto, R.I., Cohen, G.M., Green, D.R., 2000. Heat-shock protein 70 inhibits apoptosis by preventing recruitment of procaspase-9 to the Apaf-1 apoptosome. Nat. Cell Biol. 2, 469-475.

Bhattarai, N., Gunn, J., Zhang, M., 2010. Chitosan-based hydrogels for controlled localized drug delivery. Adv. Drug Deliv. Rev. 62, 83-99.

Biamonte, M.A., Van de Water, R., Arndt, J.W., Scannevin, R.H., Perret, D., Lee, W.C., 2010. Heat shock protein 90: inhibitors in clinical trials. J. Med. Chem. 53, 3-17.

Carlsson, J., Yuhas, J.M., 1984. Liquid-overlay culture of cellular spheroids. Recent Results Cancer Res. 95, 1-23.

Clemons, N.J., Buzzard, K., Steel, R., Anderson, R.L., 2005. Hsp72 inhibits Fasmediated apoptosis upstream of the mitochondria in type II cells. J. Biol. Chem. 280, 9005-9012.

Csaba, N., Köping-Höggård, M., Alonso, M.J., 2009. Ionically crosslinked chitosan/ tripolyphosphate nanoparticles for oligonucleotide and plasmid DNA delivery. Int. J. Pharm. 382, 205-214.

Davis, M.E., Zuckerman, J.E., Choi, C.H.J., Seligson, D., Tolcher, A., Alabi, C.A., Yen, Y., Heidel, J.D., Ribas, A., 2010. Evidence of RNAi in humans from systemically administered siRNA via targeted nanoparticles. Nature 464, 1067-1070.

de Jesús Valle, M.J., Dinis-Oliveira, R.J., Carvalho, F., Bastos, M.L., Sánchez Navarro, A 2008. Toxicological evaluation of lactose and chitosan delivered by inhalation. J. Biomater. Sci. Polym. Ed. 19, 387-397.

de la Fuente, M., Raviña, M., Paolicelli, P., Sanchez, A., Seijo, B., Alonso, M.J., 2010 Chitosan-based nanostructures: a delivery platform for ocular therapeutics. Adv. Drug Deliv. Rev. 62, 100-117.

El Andaloussi, S., Lakhal, S., Mäger, I., Wood, M.J., 2012. Exosomes for targeted siRNA delivery across biological barriers. Adv. Drug Deliv. Rev., doi: http://dx.doi.org/ 10.1016/j.addr.2012.08.008.

Fernandes, J.C., Qiu, X., Winnik, F.M., Benderdour, M., Zhang, X., Dai, K., Shi, Q., 2012. Low molecular weight chitosan conjugated with folate for siRNA delivery in vitro: optimization studies. Int. J. Nanomedicine 7, 5833-5845.

Friedrich, J., Seidel, C., Ebner, R., Kunz-Schughart, L.A., 2009. Spheroid-based drug screen: considerations and practical approach. Nat. Protoc. 4, 309-324.

Fukuda, J., Khademhosseini, A., Yeo, Y., Yang, X., Yeh, J., Eng, G., Blumling, J., Wang, C.F., Kohane, D.S., Langer, R., 2006. Micromolding of photocrosslinkable chitosan hydrogel for spheroid microarray and co-cultures. Biomaterials 27, 5259-5267.

Gabai, V.L., Budagova, K.R., Sherman, M.Y., 2005. Increased expression of the major heat shock protein Hsp72 in human prostate carcinoma cells is dispensable for their viability but confers resistance to a variety of anticancer agents. Oncogene $24,3328-3338$

Ge, P., Ji, X., Ding, Y., Wang, X., Fu, S., Meng, F., Jin, X., Ling, F., Luo, Y., 2010. Celastrol causes apoptosis and cell cycle arrest in rat glioma cells. Neurol. Res. 32, 94100.

Goloudina, A.R., Demidov, O.N., Garrido, C., 2012. Inhibition of HSP70: a challenging anti-cancer strategy. Cancer Lett. 325, 117-124.
Gotoh, T., Terada, K., Oyadomari, S., Mori, M., 2004. Hsp70-DnaJ chaperone pair prevents nitric oxide- and CHOP-induced apoptosis by inhibiting translocation of Bax to mitochondria. Cell Death Differ. 11, 390-402.

Guo, F., Rocha, K., Bali, P., Pranpat, M., Fiskus, W., Boyapalle, S., Kumaraswamy, S., Balasis, M., Greedy, B., Armitage, E.S., Lawrence, N., Bhalla, K., 2005. Abrogation of heat shock protein 70 induction as a strategy to increase antileukemia activity of heat shock protein 90 inhibitor 17-allylamino-demethoxy geldanamycin. Cancer Res. 65, 10536-10544.

Han, L., Zhao, J., Zhang, X., Cao, W., Hu, X., Zou, G., Duan, X., Liang, X.J., 2012. Enhanced siRNA delivery and silencing gold-chitosan nanosystem with surface charge-reversal polymer assembly and good biocompatibility. ACS Nano 6, 7340-7351.

Hanahan, D., Weinberg, R.A., 2000. The hallmarks of cancer. Cell 100, 57-70.

Hanahan, D., Weinberg, R.A., 2011. Hallmarks of cancer: the next generation. Cell 144, 646-674

Hirschhaeuser, F., Menne, H., Dittfeld, C., West, J., Mueller-Klieser, W., KunzSchughart, L.A., 2010. Multicellular tumor spheroids: an underestimated tool is catching up again. J. Biotechnol. 148, 3-15.

Holzerny, P., Ajdini, B., Heusermann, W., Bruno, K., Schuleit, M., Meinel, L., Keller, M. 2012. Biophysical properties of chitosan/siRNA polyplexes: profiling the polymer/siRNA interactions and bioactivity. J. Controlled Release 157, 297-304.

Huang, Y., Zhou, Y., Fan, Y., Zhou, D., 2008. Celastrol inhibits the growth of human glioma xenografts in nude mice through suppressing VEGFR expression. Cancer Lett. 264, 101-106.

Ivascu, A., Kubbies, M., 2006. Rapid generation of single-tumor spheroids for highthroughput cell function and toxicity analysis. J. Biomol. Screen. 11, 922-932.

Janin, Y.L., 2010. ATPase inhibitors of heat-shock protein 90, second season. Drug Discov. Today 15, 342-353.

Jayakumar, R., Prabaharan, M., Sudheesh Kumar, P.T., Nair, S.V., Tamura, H., 2011. Biomaterials based on chitin and chitosan in wound dressing applications. Biotechnol. Adv. 29, 322-337.

Jørgensen, J.A., Hovig, E., Bøe, S.L., 2012. Potent gene silencing in vitro at physiological pH using chitosan polymers. Nucleic Acid Ther. 22, 96-102.

Katas, H., Alpar, H.O., 2006. Development and characterisation of chitosan nanoparticles for siRNA delivery. J. Controlled Release 115, 216-225.

Khaitan, D., Chandna, S., Arya, M.B., Dwarakanath, B.S., 2006. Establishment and characterization of multicellular spheroids from a human glioma cell line; implications for tumor therapy. J. Transl. Med. 4, 12.

Kim, I.Y., Seo, S.J., Moon, H.S., Yoo, M.K., Park, I.Y., Kim, B.C., Cho, C.S., 2008. Chitosan and its derivatives for tissue engineering applications. Biotechnol. Adv. 26, 121.

Krauland, A.H., Alonso, M.J., 2007. Chitosan/cyclodextrin nanoparticles as macromolecular drug delivery system. Int. J. Pharm. 340, 134-142.

Leung, R.K., Whittaker, P.A., 2005. RNA interference: from gene silencing to genespecific therapeutics. Pharmacol. Ther. 107, 222-239.

Lord, M.S., Cheng, B., McCarthy, S.J., Jung, M., Whitelock, J.M., 2011. The modulation of platelet adhesion and activation by chitosan through plasma and extracellular matrix proteins. Biomaterials 32, 6655-6662.

Lu, Z., Jin, Y., Qiu, L., Lai, Y., Pan, J., 2010. Celastrol, a novel HSP90 inhibitor, depletes $\mathrm{Bcr}-\mathrm{Abl}$ and induces apoptosis in imatinib-resistant chronic myelogenous leukemia cells harboring T315I mutation. Cancer Lett. 290, 182-191.

Malmo, J., Sørgård, H., Vårum, K.M., Strand, S.P., 2012. SiRNA delivery with chitosan nanoparticles: Molecular properties favoring efficient gene silencing. J. Controlled Release 158, 261-268.

McCollum, A.K., Lukasiewicz, K.B., Teneyck, C.J., Lingle, W.L., Toft, D.O., Erlichman, C., 2008. Cisplatin abrogates the geldanamycin-induced heat shock response. Mol. Cancer Ther. 7, 3256-3264.

Mehta, G., Hsiao, A.Y., Ingram, M., Luker, G.D., Takayama, S., 2012. Opportunities and challenges for use of tumor spheroids as models to test drug delivery and efficacy. J. Controlled Release 164, 192-204.

Mittnacht, U., Hartmann, H., Hein, S., Oliveria, H., Dong, M., Pêgo, A.P., Kjems, J., Horward, K.A., Schlosshauer, B., 2010. Chitosan/siRNA nanoparticles biofunctionalize nerve implants and enable neurite outgrowth. Nano Lett. 10, 3933-3939.

Mou, H., Zheng, Y., Zhao, P., Bao, H., Fang, W., Xu, N., 2011. Celastrol induces apoptosis in non-small-cell lung cancer A549 cells through activation of mitochondria- and Fas/FasL-mediated pathways. Toxicol. In Vitro 25, 10271032.

Onozuka, H., Tsuchihara, K., Esumi, H., 2011. Hypoglycemic/hypoxic condition in vitro mimicking the tumor microenvironment markedly reduced the efficacy of anticancer drugs. Cancer Sci. 102, 975-982.

Park, S., Jeong, E.J., Lee, J., Rhim, T., Lee, S.K., Lee, K.Y., 013. Preparation and characterization of nonaarginine-modified chitosan nanoparticles for siRNA delivery. Carbohydr. Polym. 92 (1), 57-62.

Peng, B., Xu, L., Cao, F., Wei, T., Yang, C., Uzan, G., Zhang, D., 2010. HSP90 inhibitor celastrol, arrests human monocytic leukemia cell U937 at G0/G1 in thiolcontaining agents reversible way. Mol. Cancer 9, 79.

Portt, L., Norman, G., Clapp, C., Greenwood, M., Greenwood, M.T., 2011. Antiapoptosis and cell survival: a review. Biochim. Biophys. Acta 1813, 238-259.

Powers, M.V., Clarke, P.A., Workman, P., 2008. Dual targeting of HSC70 and HSP72 inhibits HSP90 function and induces tumor-specific apoptosis. Cancer Cell 14, 250-262.

Sreedhar, A.S., Csermely, P., 2004. Heat shock proteins in the regulation of apoptosis: new strategies in tumor therapy: a comprehensive review. Pharmacol. Ther. 101, 227-257. 
Tan, M.L., Choong, P.F., Dass, C.R., 2009. Cancer, chitosan nanoparticles and catalytic nucleic acids. J. Pharm. Pharmacol. 61, 3-12.

Travers, J., Sharp, S., Workman, P., 2012. HSP90 inhibition: two-pronged exploitation of cancer dependencies. Drug Discov. Today 17, 242-252.

van den Boorn, J.G., Schlee, M., Coch, C., Hartmann, G., 2011. SiRNA delivery with exosome nanoparticles. Nat. Biotechnol. 29, 325-326.

Westerheide, S.D., Bosman, J.D., Mbadugha, B.N., Kawahara, T.L., Matsumoto, G., Kim, S., Gu, W., Devlin, J.P., Silverman, R.B., Morimoto, R.I., 2004. Celastrols as inducers of the heat shock response and cytoprotection. J. Biol. Chem. 279, 56053-56060

Whitesell, L., Lindquist, S.L., 2005. HSP90 and the chaperoning of cancer. Nat. Rev. Cancer 5, 761-772.

Xiang, T.X., Li, Y., Jiang, Z., Huang, A.L., Luo, C., Zhan, B., Wang, P.L., Tao, X.H., 2008. RNA interference-mediated silencing of the Hsp70 gene inhibits human gastric cancer cell growth and induces apoptosis in vitro and in vivo. Tumori 94, 539550.
Yang, X., Wang, J., Zhou, Y., Wang, Y., Wang, S., Zhang, W., 2012. Hsp70 promotes chemoresistance by blocking Bax mitochondrial translocation in ovarian cancer cells. Cancer Lett. 321, 137-143.

Yeh, H.Y., Liu, B.H., Hsu, S.H., 2012. The calcium-dependent regulation of spheroid formation and cardiomyogenic differentiation for MSCs on chitosan membranes. Biomaterials 33, 8943-8954.

Yohannes, G., Jussila, M., Hartonen, K., Riekkola, M.L., 2011. Asymmetrical flow field-flow fractionation technique for separation and characterization of biopolymers and bioparticles. J. Chromatogr. A 1218, 4104-4116.

Zhang, J., Xia, W., Liu, P., Cheng, Q., Tahirou, T., Gu, W., Li, B., 2010. Chitosan modification and pharmaceutical/biomedical applications. Mar. Drugs. 8, 1962 1987.

Zhang, S., Zhao, B., Jiang, H., Wang, B., Ma, B., 2007. Cationic lipids and polymers mediated vectors for delivery of siRNA. J. Controlled Release 123, 1-10. 